\title{
The Impact of Corporate Brand Identity on Employee Satisfaction: Application of Coleman's model in Sri Lankan Banking Sector
}

\author{
H.K.M.N. Perera ${ }^{1 *}$ and M.R.K.N. Yatigammana ${ }^{2}$ \\ ${ }^{1}$ Category Intern, Jaykay Marketing Services (Pvt) Ltd, Colombo, Sri Lanka. \\ ${ }^{2}$ Department of Commerce and Financial Management University of Kelaniya, Sri Lanka. \\ * Corresponding Author: methmaperera123@gmail.com
}

\begin{abstract}
Corporate brand identification emphasizes the process by which customers and employees may identify the organization as a corporate brand. Corporate brand identity management can be addressed as a key indicator for success therefore, it can be an issue if not well managed. The objective of this research is to gain a better understanding of the process of Corporate Brand Identity from employee perspective. It investigates how the different dimensions of the Corporate Brand Identity influences the satisfaction of employees. Further this study focusses on applying a corporate brand identity model into a sample consisted of 111 employees in the Sri Lankan banking sector. According to the results, it indicates a positive view of corporate brand identity amongst employee satisfaction as a model. Findings suggest corporate visual identity, brand personality, consistent communications, and human resource initiatives have a positive significant influence on employee satisfaction. Employee and client focus does not have a significant impact on employee satisfaction. Current work empirically expands previous research analyze the effects of the dimensions of corporate brand identity from an employee perspective. Results indicate that organizations should pay close attention to corporate brand identity. It gives an understanding about the importance of brand identity management to improve employee satisfaction. To explore generalization of results, conducting studies in other sectors and countries would be useful.
\end{abstract}

Keywords: Brand Personality, Corporate Brand Identity, Corporate Visual Identity, Employee Satisfaction, Human Resource Initiatives.

\section{INTRODUCTION}

The interest in corporate brand identity is growing throughout the past years with the change of technology, dynamic markets, and consumer behaviours. It is viewed as a strategic resource which helps to gain competitive advantage. The main advantage of corporate identity is it acts as an essential force that motivates the employees. (Melewar, 2003) As this is a vital concept in brand management it is not only stated the determination of the brand but also provide the success directions (Buil, Catalan, \& Martinez, 2016). Corporate identity allows the establishment of a solid corporate brand identity which leads to the loyalty of stakeholders (Blamer, 1995).
Organizations must concentrate on the corporate brand identity management as its effects on employees' satisfaction and assurance with their organization (Buil, Catalan, \& Martinez, 2016). In brand identity management employees are a vital part as they play a major role mainly in the service sector where customers and staff directly connect. The customers' general perception towards corporate brand depends on employee behaviour and service quality because of the intangible nature of services. Employees views and level of satisfaction are important to face the competition. Employee satisfaction can be addressed as an emotional state of employees 
with their job. Most of the times success of an organization mainly depends on its human resource, especially in the service sector. Therefore, it is valid for the banking sector too, and employees of a bank are a valued resource for its organization. Highly satisfied employees with their job lead to the success of banks by working with commitment and effect in a positive way to its image (Karim, Islam, \& Mahmud, 2014).

This article will serve the literature in many ways. First, this enhances research about corporate brand identity by giving insights to the limitations regarding other brand identity researches. Secondly, this addresses the perception of employees which has ignored for a long time. Also, this study provides many managerial implications. This suggests how to manage the corporate brand identity in banks as well as other organization. It is much needed to highlight the importance of a well brand identity management to sectors where the quick environmental changes happen, hard to predict exactly and instantly impact of certain decisions.

In introduction section background of the study, the problem statement, the objectives of the research and all the related information is provided for the reader to get a quick understanding of what the study is all about. Litreture review section provide previous studies help the researcher to build a foundation for the research. Those previous studies provide future research possibilities also. Researchers can give evidence about the research topic area from past studies. In research methodology section, it provides information about how the research is being conducted by using available research methods. Data Analysis In this chapter, it answers to the research problem. It is provided as a logical representation and an explanation. The collected data will be analyzed and interpret the results. Conclusion and recommendation provides the outcome of the study and recommendations for solving the research problem also provided in theoretical and practical ways. Goals that are met in the study and issues which are arise within the study also provided here. Finally, it will conclude the whole study and the results and provide suggestions to improve the situation and solve the research problem and future research opportunities.

With above stated information on importance of corporate brand identity and employees influence in service sector, the research problem came out as to which extent the corporate brand identity impact on employees' satisfaction. Mainly this article focuses on dimensions of the corporate brand identity and employee satisfaction. The empirical gap is identified as there is very little research on the application of corporate identity management even its importance increased throughout the years (Arendt \& Brettel, 2010). Also, weighty work has done exploring internal branding activities towards employees' attitudes and behaviours (Punjaisri, Wilson, \& Evanschitzky, 2009, Punjaisri \& Wilson, 2011), so understandings into brand identity management are still limited and needed more empirical evidence. Also, research in this ground has mostly discovered the perspectives of top management or brand consultants (Arendt \& Brettel, 2010, Coleman, de Chernatony, \& Christodoulides, 2015). Very few studies have done on the perspectives of employees, even though employees' performance plays a major role in the service sector as their performance brings brand promises to life. It has largely ignored for a long period of time (Buil, Catalan, \& Martinez, 2016, Punjaisri \& Wilson, 2011). At this time the finance companies also compete with the banking sector. Though state banks have extra employees it shows a slowdown in the level of knowledge and skills in compared to private banks. It is a huge disadvantage for the growth of public banks. And also, private banks fulfil and satisfy their customer needs with their high level of personal contact with them (Samaranayake, 2018). According to these facts, it reveals practical importance. There comes the practical gap that how can apply the findings into practice in Sri Lanka as there are issues existing generalizability of research findings. Most of Sri Lankan banking sector related research are based on the consumer perspective and very few studies have done on the employee perspective. Therefore, this research aims to provide understandings of the effects of brand identity management from the perspective of employees. 


\section{LITERATURE REVIEW}

\section{Corporate Identity}

Corporate identity occurred as a design idea and began to gain management interest as a design subject in the 1970s. This is directed to corporate identity being viewed as a strategic resource to build trustworthiness and support of various stakeholders and gain a competitive advantage in the business environment. There are many advantages of having a corporate identity. Some of them are as below mentioned. Corporate identity can perform as a vital force that motivates the employees. When current staff gains a better understanding of the purpose, direction, and specialness of their organization, they tend to show greater pride and provide their support to the organization. Corporate identity allows employees to adjust existing cultures with more sensitivity and to fit in new cultures after a blend or acquisition with 10 less trouble. And also, corporate identity can help companies hire high talent executives (Melewer \& Saunders, 1998). Through the corporate identity, consumers can be made aware of the quality of the product and in turn, they will give support for a company's products and brands.

\section{Corporate Brand Identity}

Corporate identity allows the establishment of a solid corporate brand identity which leads to the loyalty of stakeholders (Blamer, 1995, Markwick \& Fill, 1997). According to the findings of previous research, it demonstrates that corporate identity has put the foundation for the formation of corporate brand identity.

This research focuses on the concept of corporate brand identity which is very common in the services sector. Corporate brand identity includes a set of features and dimensions which determine how the brand acts. This has become a key concept of brand management as it provides not only the purpose of a brand but also the directions to follow. Corporate brand identity leads and denotes the basis for organizations' image and reputation. Stable corporate brand identity will lead to positive perceptions, attitudes, and behaviours of different stakeholders. As an employer, an organization's attractiveness will be influenced by the corporate brand identity.
Likewise, it can help companies to motivate their employees more and attract wellqualified candidates (Melewer T. , 2003). Not only that but also it will lead to better investments (Arendt \& Brettel, 2010).

Over the last periods of time scholars like Aaker, Chernatony, Kapferer have proposed some corporate brand identity frameworks. Aaker has defined brand identity as a unique set of brand relations that brand policymakers aim to form and maintain. In accordance with Aaker's framework (Aaker, 1996), which is mostly mentioned in the theoretical literature, brand identity contains twelve dimensions prepared with four perspectives. Those four perspectives are the brand as a product, the brand as a person, the brand as an organization, and the brand as a symbol. Kapferer defined this as a brand's meaning proposed by the firm. Kapferer (Kapferer, 2004) suggests another proposal developed with six interrelated aspects. Those six aspects are physique, relationship, reflection, self-image, culture, and personality. De Chernatony (De Chernatony, 2010) has developed another brand identity framework that has defined brand identity as how the central idea of a brand communicates to different stakeholders of the organization. He considered brand identity about five components which vision, culture, positioning, personality, and relationships with different stakeholders. Regardless of their interest, now there aren't any limitations of these brand identity frameworks. Even though they are widely referenced in the academic literature, these proposals have not been subject to empirical investigation. Some researchers put their effort to fill this gap in the last few years by developing and confirming measurement scales. The present research adapts the proposal developed by Coleman (Coleman, de Chernatony, \& Christodoulides, 2011). Those authors conceptualize brand identity as a multidimensional concept that included five dimensions. Those five dimensions are Employee and client focus, Corporate visual identity, Brand personality, Consistent communications, and Human resource initiatives. 


\section{Employee Satisfaction}

Employee satisfaction is an important component of the organizational environment, which an important element of managing employee relationships. The assessment of employee attitudes such as employee satisfaction has become a common activity in organizations in which management is concerned with the physical and psychological well-being of the people. Satisfaction results when a job facilitates the fulfillment of individual values and standards. One of the most often cited definitions of employee satisfaction is the one given by Spector according to whom employee satisfaction has to do with the way how people feel about their job and its various aspects. It has to do with the extent to which people like or dislike their job. That's why employee satisfaction and employee dissatisfaction can appear in any given work situation. Many researchers have investigated the employee satisfaction of bank employees in various countries and have observed the impact of various factors that affect it both positively and negatively. Panghal and Bhambu (Bhambu \& Panghal, 2013) conducted research on the factors that influence the employee satisfaction of employees in the banking sector in India. The factor analysis method is allowed to extract five major factors, such as salary and promotion, organizational aspects, supervisor behavior, job and working conditions, and staff behavior. The result exposes that the payment and promotion of commercial banks is a crucial factor in deciding their level of satisfaction. Employees have a strong tendency to adopt a positive supervisory behavior and pleasing organizational settings. The fitness for duty, working conditions, and other social relationships between employees, can determine their level of satisfaction in the workplace. According to Velnampy \& Sivesan (Velnampy \& Sivesan, 2012), a survey on the determinants of satisfaction of employees in the banking sector in Sri Lanka reveals that employee satisfaction can be formed by ten variables such as salary, pleasure in working, promotion, relationship with subordinate supervisor, supervisor's direction, achievement, appreciation, participation in decision-making, pride in work.
According to the previous studies, it shows that these two variables are interrelated. Research findings suggested that corporate brand identity has a positive and direct effect on employee job satisfaction. An effective corporate brand identity can increase employee satisfaction. Employee satisfaction can strengthen their sense of commitment to the organization. This will make them more engaged in their job role and take their tasks with better care (Buil, Catalan, \& Martinez, 2016, Bravo, Buil, de Chernatony, \& Martínez, 2017, Nezhad \& Gayem, 2015). However, limited literature is available in this area of corporate brand identity and perspective from employees, and it needs more empirical evidence. And also, no studies were found in the Sri Lankan context. Therefore, more research is needed to test the impact of corporate brand identity on employee satisfaction.

\section{Conceptual Framework and Hypotheses}

\section{Measures and Hypotheses}

Following research and articles used to select the most appropriate way to measure each variables. To measure the corporate brand identity items proposed by Coleman, D., de Chernatony, L., Christodoulides, G., 2011, Corporate Visual Identity Management, Annette L.M. van den Bosch, Beverly MallettHamer,2005 and A Research Report by The Society for Human Resource Management will be used. To measure employee satisfaction will be used the items proposed by Sue Hayday, IES Research Fellow.

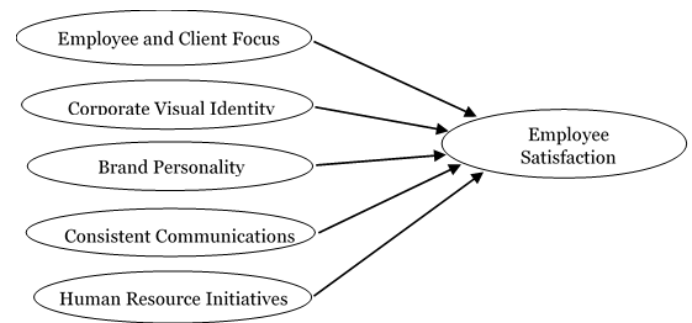

Figure 1: Conceptual Framework

Brand identity management is a key driver to employee identification which makes them satisfied within the organization. Corporate 
ISSN 2738-2028 (Online) | Vol. 5 | No. 2 | 2021 July

brand identity and its management help to create the attachment with the organization and then they become proud to be a part of that organization (Dukerich ,2002). All five dimensions that are included in corporate brand identity management may influence employees' satisfaction with the organization. Previous research based on internal branding points out that the elements like human resources initiatives are key drivers to employee satisfaction (Punjaisri, Wilson, \& Evanschitzky, 2009). And also, external dimensions such as visual identity and corporate 20 communications play a significant role in employee satisfaction. Internal branding activities such as employee training programs and communicating the brand identity values help employees to understand the corporate brand identity. Because this leads employees to be satisfied with their organization. Moreover, maintaining a stable organizational image with a good employee client focus strategy or through a clear brand personality also influence employee satisfaction. Arendt and Brettel (2010) also exposed that brand identity management is composed of value spreading, steady image, and a visual identity which creates a positive effect on employee satisfaction. All these dimensions of brand identity management present corporate brands to stakeholders and influence employee satisfaction. In the field of organizational psychology, it is assumed that the relations developed by employees towards the organization influence the way they think, feel, and behave in the workplace. So employee satisfaction is a possible outcome of the corporate brand identity of the organization. Quite a few works have found a positive relationship between corporate brand identity and their level of satisfaction (King \& Grace, 2010).

\section{H1: Employee and client focus has a positive} effect on employee satisfaction.

H2: Corporate visual identity has a positive effect on employee satisfaction.

\section{H3: Brand personality has a positive effect on employee satisfaction.}

H4: Consistent communications has a positive effect on employee satisfaction.
H5: Human resource initiatives have a positive effect on employee satisfaction.

\section{METHODOLOGY}

\section{Research Design}

Research philosophy is an important part of research methodology as it enables to decide which approach should be adopted by the research and which kind of data need to be collected and analyzed. This research comes under the positivism paradigm as this research based on a scientific procedure and support with statistical and objective data. This study is in deductive approach, quantitative type under objectivism. Based on the purpose of this research, it comes under the Hypothesis Testing research. And the type of investigation of the research is Correlational Study. This is conducted in a non-contrived setting with minimal interference. Unit of analysis is individuals as the study focuses on employees' attitudes and behaviours and it is a Crosssectional study which conducts at a particular time.

\section{Data Collection Method}

The population of this research is employees in the banking sector of Sri Lanka. The sample has narrow down to the Colombo district as most of the bank branches are located in Colombo district. As the population statistics are unknown $G$ power 3.124 software was used to calculate the sample size. According to the output from the G power tool, the sample size was chosen as 111 employees in the banking sector in the Colombo district of Sri Lanka.

Both primary and secondary data are used for this research. Primary data is collected using a survey method. So, a questionnaire is built by adopting previous researchers' questionnaires who investigated the same issue based on the survey approach. Data related to demographic factors, corporate brand identity, and satisfaction, will be collected through the questionnaire. First, 10 banks were selected according to the ranks they have for their brand name. Both public and private sector banks include in these top 10 bank brands. Then for the head office branch of each bank will be sent an email requesting their employees' email addresses. After getting employees' email 
ISSN 2738-2028 (Online) | Vol. 5 | No. 2 | 2021 July

addresses, employees from each bank selected through excel random numbers which tally with the sample size. Therefore, this study is going to use simple random sampling method. An online questionnaire has distributed among the bank employees to collect the data. Completed questionnaires has used for the analysis. Data collected from the survey will be analyzed through Statistical Package for
Social sciences (SPSS). As the statistical data analysis method, regression will be used to examine relationships among the variables. The data collection process of the research usually begins with a pilot test. In this study pilot test was conducted using a sample of 30 employees randomly selected from the target population. Following are the Validity and Reliability results from pilot test.

\section{Validity and Reliability}

Table 1: Reliability \& Validity Test

\begin{tabular}{llll}
\hline Variable & Cronbach's Alpha & AVE & CR \\
\hline Employee and Client Focus & 0.792 & 0.637 & 0.875 \\
Corporate Visual Identity & 0.764 & 0.684 & 0.865 \\
Brand Personality & 0.777 & 0.694 & 0.872 \\
Consistent Communications & 0.846 & 0.689 & 0.898 \\
Human Resource Initiatives & 0.715 & 0.639 & 0.842 \\
Employee Satisfaction & 0.900 & 0.770 & 0.931 \\
\hline
\end{tabular}

Source: Survey Data

As the Cronbach Alpha value of all variables is more than 0.7 all the variables are acceptable under the reliability test. Fornell and Larcker (1981) recommended a CR value of 0.60 or more and an AVE greater than 0.5. According to the above table CR and AVE values for all variables are above the required values.

\section{DATA ANALYSIS}

\section{Correlation Analysis}

Table 2: Correlation Analysis

\begin{tabular}{lll}
\hline & & Employee Satisfaction \\
\hline Employee and Client Focus & Pearson Correlation & $0.445^{* *}$ \\
& Sig. (1-tailed) & 0.000 \\
& N & 111 \\
Corporate Visual Identity & Pearson Correlation & $0.477^{* *}$ \\
& Sig. (1-tailed) & 0.000 \\
& N & 111 \\
Brand Personality & Pearson Correlation & $0.360^{* *}$ \\
& Sig. (1-tailed) & 0.000 \\
Consistent Communications & N & 111 \\
& Pearson Correlation & $0.450^{* *}$ \\
& Sig. (1-tailed) & 0.000 \\
Human Resource Initiatives & N & 111 \\
& Pearson Correlation & $0.471^{* *}$ \\
& Sig. (1-tailed) & 0.000 \\
& N & 111 \\
\hline$*$. Correlation is significant at the 0.01 level (1-tailed). &
\end{tabular}


According to this study, there was a statistically significant, moderate positive correlation between Employee and Client Focus and Employee Satisfaction, $\mathrm{p}<0.05$. There was a statistically significant, moderate positive correlation between Corporate Visual Identity and Employee Satisfaction, $\mathrm{p}<0.05$. There was a statistically significant, moderate positive correlation between Brand Personality and Employee Satisfaction, $\mathrm{p}<0.05$. There was a statistically significant, moderate positive correlation between Consistent Communications and Employee Satisfaction, $p$ $<0.05$. There was a statistically significant, moderate positive correlation between Human Resource Initiatives and Employee Satisfaction, $\mathrm{p}<0.05$. Therefore, all the independent variables have a moderate positive correlation with the dependent variable.

\section{Regression Analysis}

\section{$R$ Squared}

R Squared values imply predicted power of IVs about DV. If the value close to zero, that means IV cannot use to predict the DV that much. But if the value is close to one, that implies IV can be used to predict the DV. According to the Model Summary table, R Square is 0.369 . It implies that $37 \%$ of the variance of DV will be explained by the IVs together. A lower percentage means the effect on DV is less. The rest of the $63 \%$ explained by other factors that the study has not consider for this research.

\section{Model Significance (ANOVA Table)}

ANOVA table can be used to find the model fit or model significance of a study. If the ANOVA table's significance value is greater than the significance level, it means total model is not significant. If the significance value of ANOVA table is less than the significance level, that means total model fit is satisfied and model is significant. Model significance value should be less than 0.05 . The significant value of the model used in the study is 0.000 . It has a P value less than 0.05 . Therefore, the model significant for the study.

\section{Hypothesis Testing (Coefficient Table)}

Significance values of coefficient table implies the acceptance or rejection of hypothesis. Coefficient implies how independent variables individually influence the dependent variable. Significance value should be less than 0.05 . In Unstandardized Coefficients implies how much the dependent variable varies with an independent variable when all other independent variables are held constant. B value of Unstandardized Coefficients represents the slope of the line between the independent variable and the dependent variable.

Table 3: Coefficient Table

\begin{tabular}{|l|c|c|}
\hline & $\beta$ & Sig. \\
\hline $\begin{array}{l}\text { Employee and client } \\
\text { focus }\end{array}$ & 0.005 & 0.971 \\
\hline $\begin{array}{l}\text { Corporate visual } \\
\text { identity }\end{array}$ & 0.224 & 0.029 \\
\hline Brand personality & 0.176 & 0.042 \\
\hline $\begin{array}{l}\text { Consistent } \\
\text { communications }\end{array}$ & 0.229 & 0.043 \\
\hline $\begin{array}{l}\text { Human resource } \\
\text { initiatives }\end{array}$ & 0.206 & 0.044 \\
\hline
\end{tabular}

Source: Survey Data

Apart from Employee and Client Focus, all the other independent variables have a significance value less than 0.05. Employee and Client Focus has a significance value above 0.05 which is 0.971 . When considering $\beta$ value all the independent variables have a positive impact on the dependent variable. According to the above statistics impact of Employee and Client Focus on Employee Satisfaction is not supported. Impact of Corporate Visual Identity, Brand Personality, Consistent Communications and Human Resource Initiatives on Employee Satisfaction are supported.

\section{Hypotheses Testing}

H1: Employee and client focus has a positive effect on employee satisfaction.- Rejected

$\mathrm{H} 2$ : Corporate visual identity has a positive effect on employee satisfaction.- Accepted

H3: Brand personality has a positive effect on employee satisfaction - Accepted 


\section{ISSN 2738-2028 (Online) | Vol. 5 | No. 2 | 2021 July}

$\mathrm{H} 4$ : Consistent communications has a positive effect on employee satisfaction.- Accepted

H5: Human resource initiatives have a positive effect on employee satisfaction.- Accepted

\section{RESULTS AND DISCUSSION}

In the branding literature, there is little empirical research on the relationships between corporate brand identity management and employees' satisfaction. This study tests a model to gain a better understanding about these relationships. From an overall view, the result of the model shows that a positive perception of corporate brand identity amongst employee satisfaction from the organization for whom they work. This result is in line with previous research done by Buil,Catalan and Martinez in 2016 and Nezard and Gayem in 2015. Specifically, findings suggest corporate visual identity, brand personality, consistent communications and human resource initiatives have a positive influence on employee satisfaction. Even though Employee and Client Focus shows a positive impact on employee satisfaction it is not statistically significant. According to this study employee and client focus and employee satisfaction have a positive relationship, but their relationship is not significant. Since the result is not significant that hypothesis is rejected. Therefore, employee and client focus is not fit to the model. These two variables maybe not significant on population levels. It could be an issue of sample size because this study has conducted with a sample of 111 banking employees in the Colombo district. Previous researchers had used larger samples than this study. Corporate visual identity and employee satisfaction have a positive relationship according to this study. It means when the corporate visual identity increases employee satisfaction will be increased. This result is in line with the literature as well. Usually, corporate visual identity helps to create an emotional impression in employees' mind which will make them feel good about their employer brand and leads to employees' satisfaction. Therefore, this can consider as a suitable measurement to measure employee satisfaction. This study was found that brand personality has a significant impact on customer satisfaction. It means it is suitable to measure the employee satisfaction. As it has a positive relationship with employee satisfaction when brand personality increases while other factors are constant employee satisfaction will be increased. This result is in line with the literature as well. Consistent communications also demonstrate a positive and significant relationship with employee satisfaction. It means when the consistent communications increase employee satisfaction will be increased. This result is in line with the literature as well. Receiving accurate information will impact employee satisfaction positively as it makes employees comfortable with working environment. This study emphasized that human resource initiatives and employee satisfaction have a positive relationship and human resource initiatives have a significant impact on employee satisfaction. This result is in line with the literature as well. It means this dimension of corporate brand identity is also suitable to measure the employee satisfaction. While other factors remain constant when the human resource initiatives increase employee satisfaction will be increased. Human resource initiatives improve employee performance and keep them happy at work. Therefore, Corporate Visual Identity, Brand Personality, Consistent Communications and Human Resource Initiatives shows the same results as in research of Buil, Catalán, \& Martínez. According to past studies most influencing independent variables are human resource initiatives and employee client focus (Buil, Catalan, \& Martinez, 2016, Punjaisri, Wilson, \& Evanschitzky, 2009). But according to this study, most influencing independent variable is consistence communications. It has the highest unstandardized coefficient $\beta$ value (0.229) Therefore, according to different context the amount of impact of independent variables on dependent variable can be varied.

\section{CONCLUSION}

The aim of this study is to identify the impact of corporate brand identity on employee satisfaction in the banking sector in Sri Lanka. Apart from the impact of employee and client focus on employee satisfaction all the other findings of this research are in line with the past studies. As a model, it reveals a significant impact on employee satisfaction. Only 
employee and client focus demonstrate an insignificant impact on employee satisfaction while all other dimensions of corporate brand identity indicate a positive impact on employee satisfaction. Therefore, it can be concluded that future researchers can use corporate visual identity, brand personality, consistent communications and human resource initiatives as factors which affecting employee satisfaction. When considering about the employee and client focus, there may be a sample size issue.

\section{THEORETICAL AND MANAGERIAL IMPLICATIONS}

These results have implications for both academics and managers. From a theoretical point of view, this study enriches the search for the corporate brand identity that addresses certain previous limitations compared to other studies on brand identity. From an employee perspective, it takes an empirical outlook. As explained in literature, this fact is mostly relevant because the role of employees has been ignored for a longer time of period. It is important in the creation and communication of the corporate brand identity. This gives more insight and also provide proof that there is a relationship between these two variables and as a model it is significant. The research findings also have several management implications. First of all, it emphasized the relevance of brand identity for the organization, as well as the operationalization of this construction. Traditional branding management has been the main concern of many managers. The interdependent relationship demonstrates the benefits of good identity management. However, it is better if managers can take this relevant concept into account. This recommendation is even more important in the financial field and service sector. In this period of time a low level of differentiation has given to financial products and services. And the global economic crisis is also impacting these sectors severely. These situations create an environment of uncertainty and mistrust. Therefore, discussing and focusing on a well brand identity management is really important. This research provides guidance for managers seeking to identify key dimensions in which should focus. The results suggest that not only the tangible aspects but also aspects such as visual identity and dimensions that are more directly related to employees, such as human resource initiatives are relevant. It is also important that organizations pay attention to both customer and employee needs. In addition, it is essential to create training programs designed to develop skills necessary to deepen relationships with customers. Moreover, management must be aware that a brand or an organization without personality lacks identity. Accordingly, organizations should focus on supportive partnerships and traits, which will allow them to differentiate themselves from others. Finally, it is very important that the organization establishes a clear and measured process for corporate communication. These implications will strengthen connections between employees and the organization and improve their satisfaction.

\section{FUTURE RESEARCH}

There are several limitations of this study which suggest instructions for future research. Even though this study contributes insights practically, the following limitations were identified. First, this was conducted in the banking sector of Sri Lanka. And the sample is narrow down to the western province banking employees. This sector has different features compared to other sectors. This makes the generalizability limited to this context. Therefore, it is needed to be considered about the application of these findings in other sectors and in other countries in future research. Future researchers can go upon a larger sample of banking employees to provide more generalizable results and more significant outcomes. Adding some other independent variables which have not used in this study will be provided a much better understanding and insight into the research problem. Further, this research can be done as a qualitative research design to present a depth analysis.

\section{REFERENCES}

Aaker, A. (1996). Building Strong Brands. New York: The free press.

Arendt, S., \& Brettel, M. (2010). Understanding the influence of corporate 
ISSN 2738-2028 (Online) | Vol. 5 | No. 2 | 2021 July

social responsibility on corporate identity, image, and firm performance. Management Decision, 1469-1492.

Bhambu, S., \& Panghal, S. (2013). Job satisfaction in Indian Public Sector Banks. International Journal of New Innovations in Engineering and Technology.

Blamer, J. M. (1995). Corporate Branding and Connoisseurship. Journal of General , 21(1), 24-46.

Bravo, R., Buil, I., de Chernatony, L., \& Martínez, E. (2017). Managing brand identity: effects on the employees. International Journal of Bank Marketing, 2-23.

Buil, I., Catalan, S., \& Martinez, E. (2016). The importance of corporate brand identity in business management: An application to the UK banking sector. Business Research Quarterly, 3-12.

Coleman, D. A., de Chernatony, L., \& Christodoulides, G. (2015). B2B service brand identity and brand performance: $A n$ empirical investigation in the UK's B2B IT services sector. European Journal of Marketing, Vol. 49 No. 7/8, pp. 11391162.

Coleman, D., de Chernatony, L., \& Christodoulides, G. (2011). B2B service brand identity: Scale development and validation. Industrial Marketing Management, 1063-1071.

De Chernatony, L. (2010). From Brand Vision to Brand Evaluation.

Kapferer, J. (2004). The New Strategic Brand Management. London.

Karim, M. M., Islam, M. J., \& Mahmud, M. L. (2014). Job Satisfaction of Employees. European Journal of Business and Management, Vol.6, No.17.

King, C., \& Grace, D. (2010). Building and measuring employee-based brand equity. European Journal of Marketing, 938-971.

Markwick, N., \& Fill, C. (1997). Towards a framework for managing corporate identity. European Journal of Marketing, 396-409.
Melewer, T. (2003). Determinants of the corporate identity construct: a review of the literature. Journal of Marketing Communications, 195-220.

Melewer, T. C., \& Saunders, J. (1998). Global corporate visual identity system: using an extended mareting mix. European Journal of Marketing, 538-550.

Nezhad, R. M., \& Gayem, A. (2015). The Impact of the Corporate Brand Identity on Employee Behavior and Attitude: A Descriptive Analysis. INTERNATIONAL JOURNAL OF HUMANITIES AND CULTURAL STUDIES, 400-412.

Punjaisri, K., \& Wilson, A. (2011). Internal branding process:key mechanisms, outcomes and moderating factors. European Journal of Marketing, Vol. 45 No. 9/10, pp. 1521-1537.

Punjaisri, K., Wilson, K., \& Evanschitzky, H. (2009). Internal branding to influence employees' brand promise delivery: a case study in Thailand. Journal of Service Management, Vol. 20 No. 5, pp. 561-579.

Samaranayake, C. (2018, February 02). Looking ahead for the Sri Lankan Banking Looking ahead for the Sri Lankan Banking. Retrieved from Daily News.

Velnampy, T., \& Sivesan, S. (2012). Determinants of Employees' Job Satisfaction: A Study of Banking Industries in Sri Lanka. 